Supporting Information for:

\title{
Structure Analyses of Dodecylated Single-Walled Carbon Nanotubes
}

Feng Liang, Lawrence B. Alemany, Jonathan M. Beach

and W. Edward Billups*

Department of Chemistry and Center for Nanoscale Science and Technology,

Rice University, Houston, Texas 77005

billups@rice.edu 

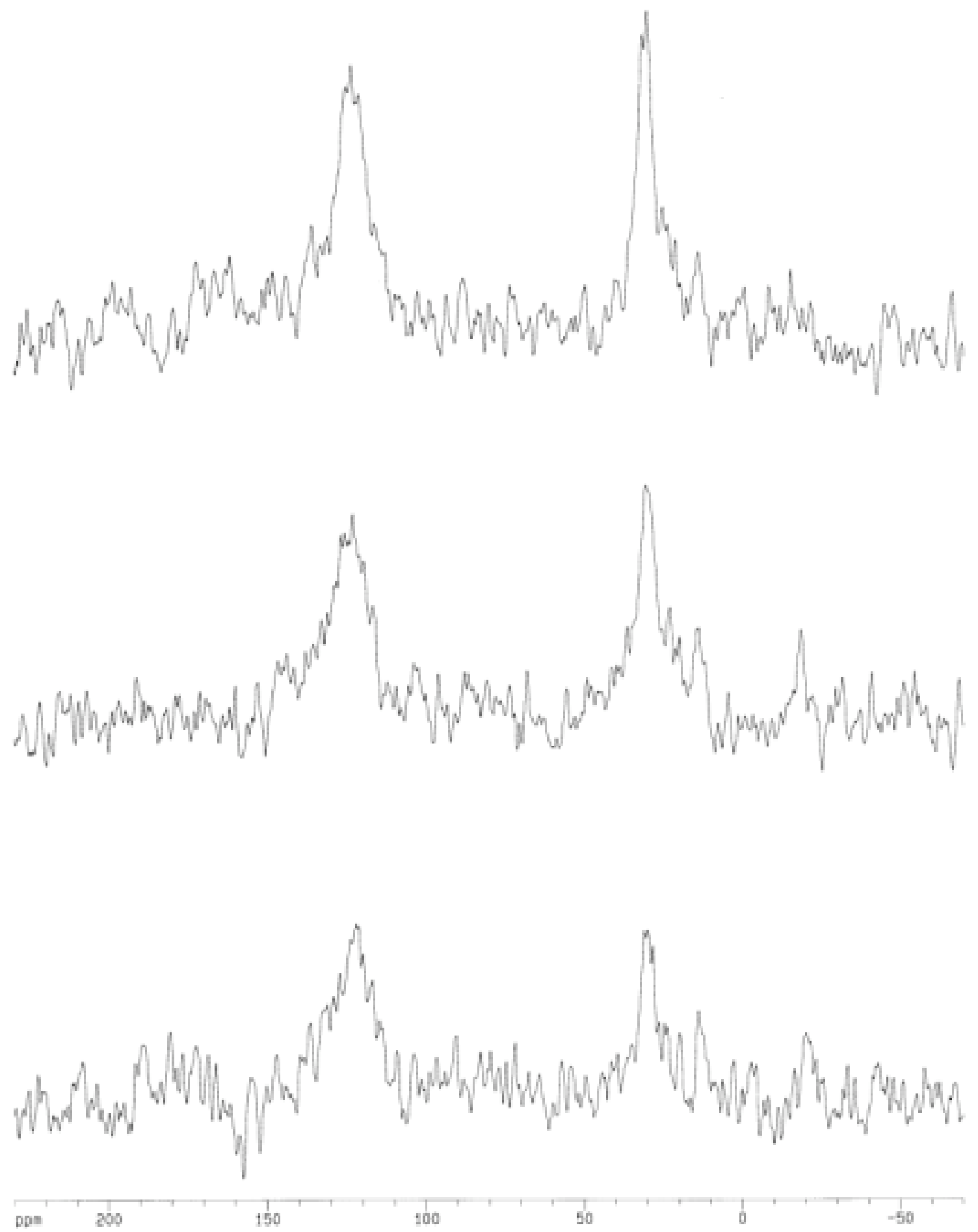

Figure S-1. Dodecylated SWNTs prepared by $\mathrm{Na} / \mathrm{NH}_{3}$ reductive alkylation with $n-\mathrm{C}_{12} \mathrm{H}_{25} \mathrm{I}$. Proceeding down: ${ }^{1} \mathrm{H}-{ }^{13} \mathrm{C}$ CPMAS spectrum with a $50-\mu \mathrm{s}, 60-\mu \mathrm{s}$, or $80-\mu \mathrm{s}$ dephasing delay before FID acquisition. 


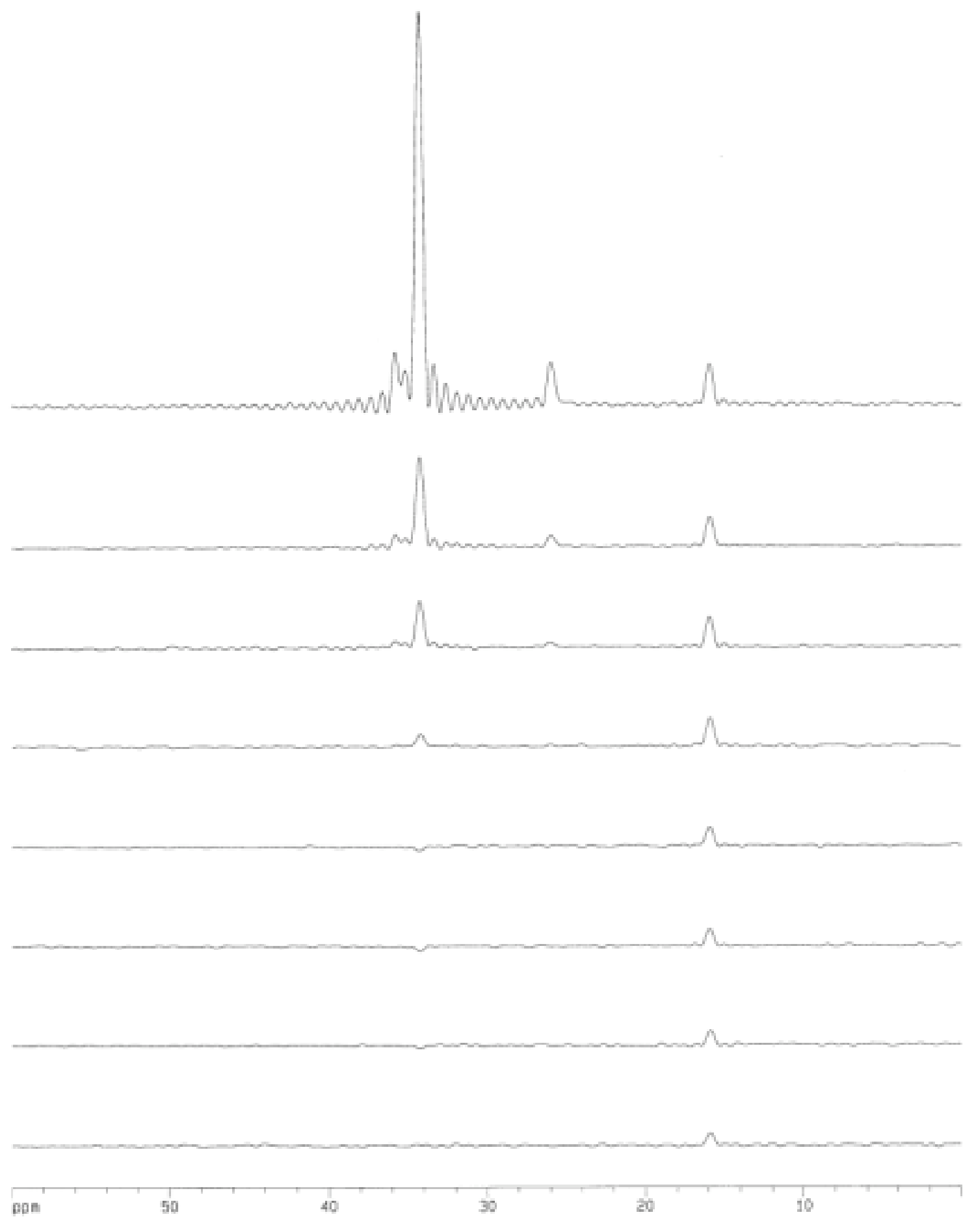

Figure S-2. $n-\mathrm{C}_{24} \mathrm{H}_{50}$. Top: Basic ${ }^{1} \mathrm{H}-{ }^{13} \mathrm{C}$ CPMAS spectrum. Proceeding down: ${ }^{1} \mathrm{H}-{ }^{13} \mathrm{C}$ CPMAS spectrum with a $10-\mu \mathrm{s}, 20-\mu \mathrm{s}, 30-\mu \mathrm{s}, 40-\mu \mathrm{s}, 50-\mu \mathrm{s}, 60-\mu \mathrm{s}$, or $80-\mu \mathrm{s}$ dephasing delay before FID acquisition. 

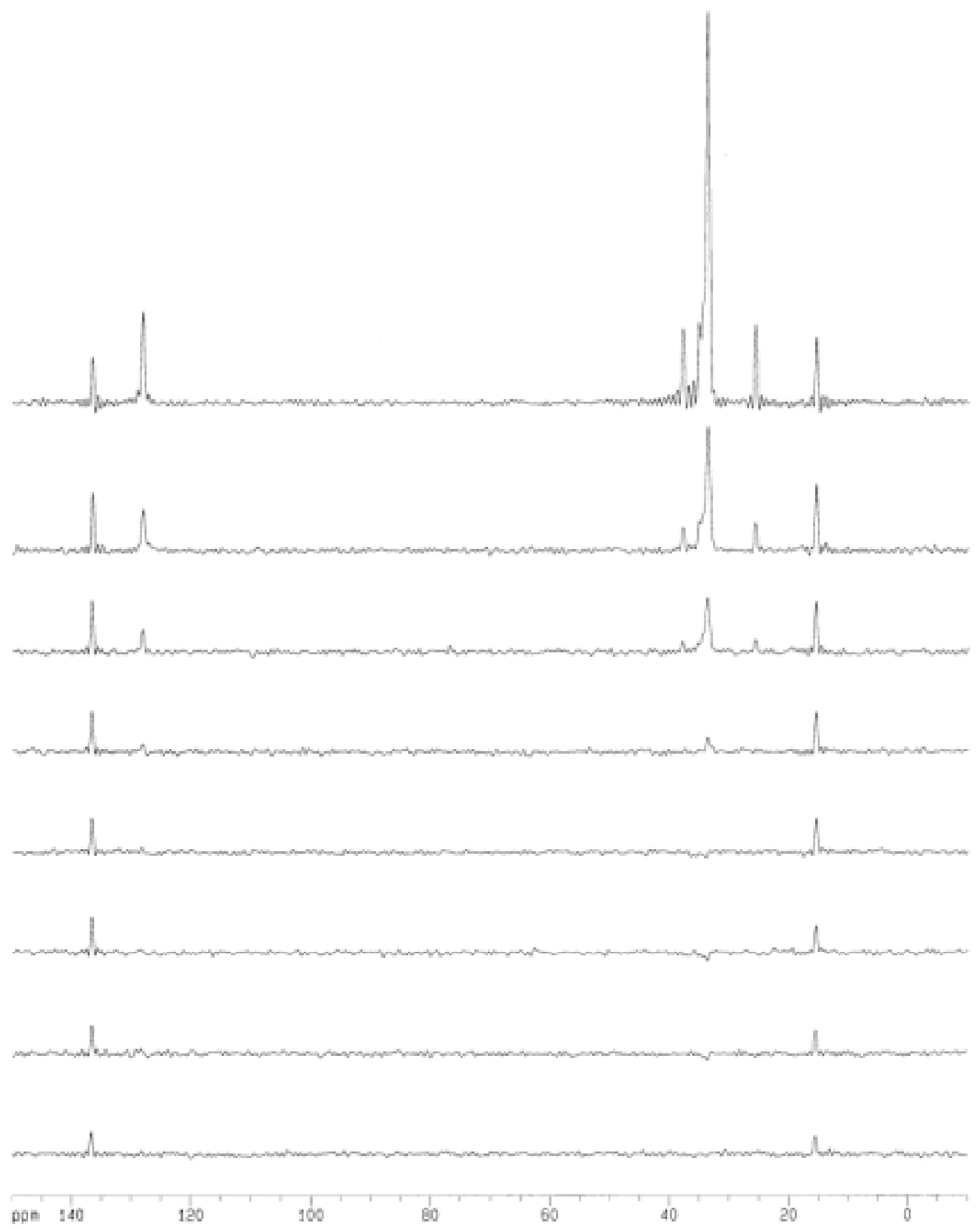

Figure S-3. 1,4-Didodecylbenzene. Top: Basic ${ }^{1} \mathrm{H}-{ }^{13} \mathrm{C}$ CPMAS spectrum. Proceeding down: ${ }^{1} \mathrm{H}-{ }^{13} \mathrm{C}$ CPMAS spectrum with a $10-\mu \mathrm{s}, 20-\mu \mathrm{s}, 30-\mu \mathrm{s}, 40-\mu \mathrm{s}, 50-\mu \mathrm{s}, 60-\mu \mathrm{s}$, or $80-\mu \mathrm{s}$ dephasing delay before FID acquisition. 
Discussion of the following areas follows in order to provide background information useful for analyzing the spectra of the dodecylated SWNTs:

- ${ }^{13} \mathrm{C}$ NMR data of $\mathrm{C}_{60}$ and $\mathrm{C}_{70}$ derivatives

- 1,2- and 1,4-addition patterns in di- and higher substituted derivatives of $\mathrm{C}_{60}$ and $\mathrm{C}_{70}$

- Estimating the quaternary aliphatic carbon chemical shift in dodecylated SWNTs

- Ring current effects on ${ }^{13} \mathrm{C}$ and ${ }^{1} \mathrm{H}$ chemical shifts

\section{${ }^{13} \mathrm{C}$ NMR data in $\mathrm{C}_{60}$ and $\mathrm{C}_{70}$ derivatives}

A substantial amount of ${ }^{13} \mathrm{C}$ NMR data has been reported for $\mathrm{C}_{60}$ and $\mathrm{C}_{70}$ derivatives bearing two, four, six, or eight $-\mathrm{CH}_{2} \mathrm{Z}$ substituents, i.e., methyl, ${ }^{13}$ primary alkyl, ${ }^{13 b, 14}$ allyl, ${ }^{15}$ or benzyl ${ }^{14 c, 15 b, 16}$ groups. Fullerene derivatives with long chain primary alkyl substituents would be the best for comparing against dodecylated SWNTs, but little ${ }^{13} \mathrm{C}$ NMR data appear to be available for such compounds. Specifically, the methylene carbon adjacent to the cage in $1,4-\mathrm{C}_{60}\left[\left(\mathrm{CH}_{2}\right)_{6} \mathrm{X}\right]_{2}, \mathrm{X}=\mathrm{Cl}$ or $\mathrm{I}$, apparently gives a signal at $\delta 43.6$, while the quaternary aliphatic carbon apparently gives a signal at 859.5. ${ }^{14 \mathrm{~b}}$ (1,4-Addition corresponds to adding functional groups across a 6-membered ring-Figure S-4.) The quaternary aliphatic carbons bearing the $-\mathrm{CH}_{2} \mathrm{Z}$ substituents often appear near $\delta 60$ in derivatives of $\mathrm{C}_{60}$ and the considerably fewer derivatives of $\mathrm{C}_{70}$, but signals as far upfield as $\delta 55^{15 \mathrm{a}}$ and $\delta 53^{13 \mathrm{c}}$ have been reported for the quaternary aliphatic carbons of such derivatives of $\mathrm{C}_{60}$ and $\mathrm{C}_{70}$, respectively. These quaternary aliphatic carbon signals are downfield of the region where strong signals appear for the quaternary aliphatic carbons of the dodecylated SWNTs. 

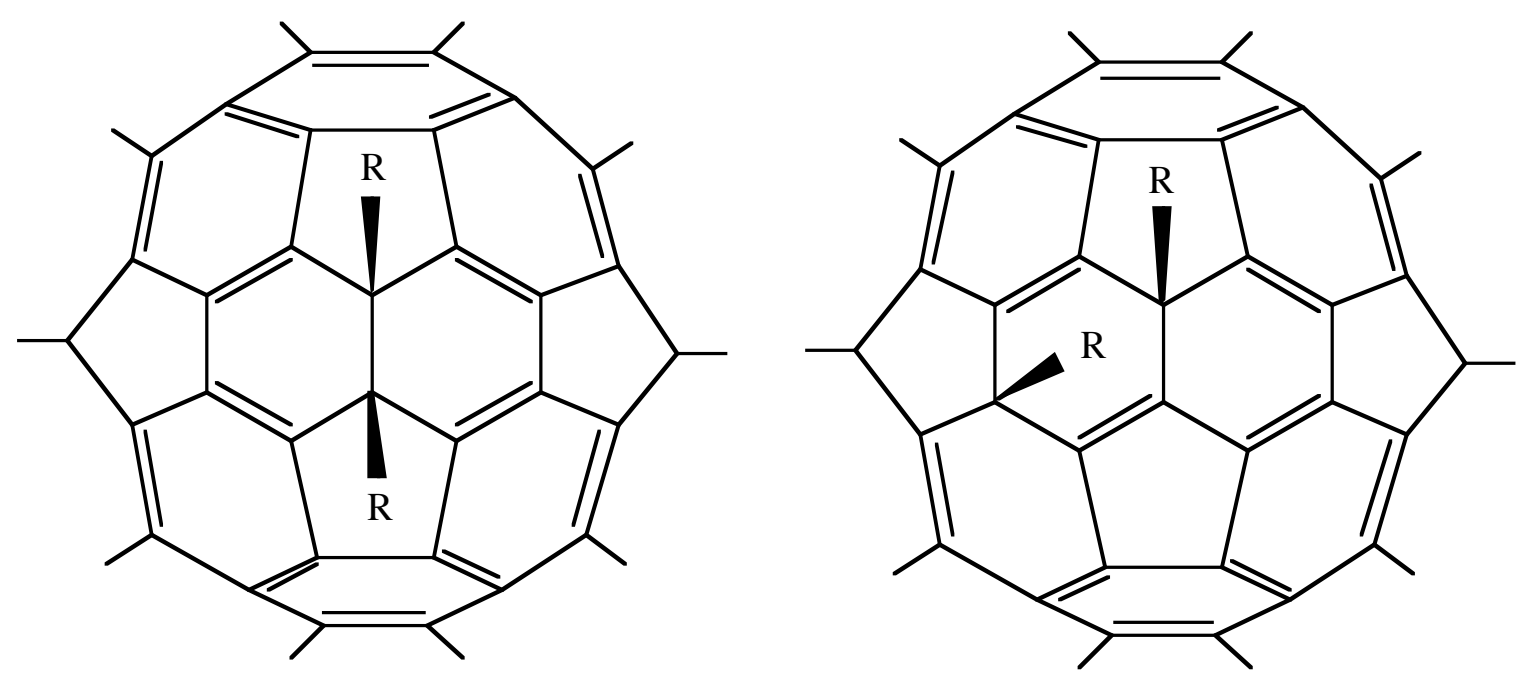

Figure S-4. Left: 1,2-addition to a bond shared by two 6-membered rings in $\mathrm{C}_{60}$. Right: 1,4-addition across a 6-membered ring in $\mathrm{C}_{60}$.

Nearly a decade ago, Wang et al. ${ }^{14 a}$ noted that the quaternary aliphatic carbon of a 1,4disubstituted $\mathrm{C}_{60}$ derivative with two identical alkyl groups gives a signal about 5-7 ppm upfield of the quaternary aliphatic carbon in the corresponding 1,2-disubstituted $\mathrm{C}_{60}$ derivative with one alkyl group and one hydrogen. (1,2-Addition results from adding functional groups to a bond shared by two 6membered rings-Figure S-4.) More recent reports continue to show this pattern (Table S-1). However, of particular interest for our work on dodecylated SWNTs, these recent reports also show that the quaternary aliphatic carbon of a 1,4-disubstituted $\mathrm{C}_{60}$ derivative with two identical $\mathrm{CH}_{2} \mathrm{Z}$ groups gives a signal 7-15 ppm upfield of the quaternary aliphatic carbon in the corresponding 1,2disubstituted $\mathrm{C}_{60}$ derivative (Table $\mathrm{S}-1$ ). The quaternary aliphatic carbon signal in the 1,2-dibenzyl $\mathrm{C}_{60}$ derivative is exceptionally deshielded ( $\delta 75.5)$ compared to that in the 1,4 -addition product $(\delta 60.4)^{16 \mathrm{c}}$ or in the 1,2-dibenzyl $\mathrm{C}_{70}$ derivative ( $\delta 60.97$ and $\left.\delta 60.22\right) .{ }^{15 \mathrm{~b}} \quad$ The sensitivity of chemical shift to small structural perturbations is also evident from the reported ${ }^{1} \mathrm{H}$ chemical shifts for the benzylic protons of other fullerene derivatives. ${ }^{23}$ ( ${ }^{13} \mathrm{C}$ NMR data were not reported.) 
Table S-1. Quaternary Aliphatic Carbon Chemical Shifts in 1,2- and 1,4-Disubstituted $\mathrm{C}_{60}$ Derivatives with $\mathrm{CH}_{2} \mathrm{Z}$ Substituents ${ }^{\mathrm{a}}$

\begin{tabular}{|c|c|c|c|}
\hline $\mathrm{CH}_{2} \mathrm{Z}$ & $1,2-\mathrm{C}_{60}\left(\mathrm{CH}_{2} \mathrm{Z}\right)_{2}$ & $1,2-\mathrm{C}_{60} \mathrm{H}\left(\mathrm{CH}_{2} \mathrm{Z}\right)$ & $1,4-\mathrm{C}_{60}\left(\mathrm{CH}_{2} \mathrm{Z}\right)_{2}$ \\
\hline $\mathrm{CH}_{2} \mathrm{CH}_{3}$ & $\begin{array}{l}67 \\
\text { in } \mathrm{C}_{6} \mathrm{D}_{6} / \mathrm{CS}_{2}{ }^{\mathrm{b}}\end{array}$ & $\begin{array}{l}65.55 \\
\text { in } o-\mathrm{C}_{6} \mathrm{D}_{4} \mathrm{Cl}_{2}{ }^{\mathrm{c}}\end{array}$ & $\begin{array}{l}60.18 \\
\text { in } \mathrm{C}_{6} \mathrm{D}_{6} / \mathrm{CS}_{2}{ }^{\mathrm{b}}\end{array}$ \\
\hline $\mathrm{CH}_{2} \mathrm{COOCH}_{2} \mathrm{CH}_{3}$ & $\begin{array}{l}62.7 \text { or } 61.8 \\
\text { in } \mathrm{CDCl}_{3}{ }^{\mathrm{d}}\end{array}$ & $\begin{array}{l}61.39 \\
\text { in } \mathrm{CDCl}_{3}{ }^{\mathrm{e}}\end{array}$ & $\begin{array}{l}54.81 \\
\text { in } \mathrm{CDCl}_{3}{ }^{\mathrm{f}}\end{array}$ \\
\hline$\overline{\mathrm{CH}_{2} \mathrm{C}_{6} \mathrm{H}_{5}}$ & $\begin{array}{l}75.5 \\
\text { in } \mathrm{CS}_{2} / \mathrm{CDCl}_{3}{ }^{\mathrm{g}}\end{array}$ & $\begin{array}{l}66.0 \\
\text { in } \mathrm{CS}_{2} / \mathrm{CDCl}_{3}{ }^{\mathrm{h}}\end{array}$ & $\begin{array}{l}60.4 \\
\text { in } \mathrm{CS}_{2} / \mathrm{CDCl}_{3}{ }^{\mathrm{i}}\end{array}$ \\
\hline
\end{tabular}

${ }^{a}$ Where chemical shift data have been reported more than once, the cited reference was chosen so that the same solvent was used for all three derivatives.

bAllard, E.; Rivière, L.; Delaunay, J.; Dubois, D.; Cousseau, J. Tetrahedron Lett. 1999, 40, 7223-7226.

'Siedschlag, C.; Luftmann, H.; Wolff, C.; Mattay, J. Tetrahedron 1999, 55, 7805-7818.

dAllard, E.; Delaunay, J.; Cousseau, J. Org. Lett. 2003, 5, 2239-2242.

${ }^{\text {e} M i k a m i, ~ K . ; ~ M a t s u m o t o, ~ S . ; ~ I s h i d a, ~ A . ; ~ T a k a m u k u, ~ S . ; ~ S u e n o b u, ~ T . ; ~ F u k u z u m i, ~ S . ~ J . ~ A m . ~ C h e m . ~ S o c . ~}$ 1995, 117, 11134-11141. See also: Wang, G.-W.; Murata, Y.; Komatsu, K.; Wan, T. S. M. Chem. Commun. 1996, 2059-2060; Wang, Z.; Meier, M. S. J. Org. Chem. 2003, 68, 3043-3048.

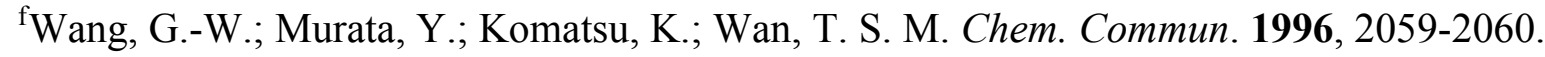

${ }^{\mathrm{g}}$ Kadish, K. M.; Gao, X.; Van Caemelbecke, E.; Suenobu, T.; Fukuzumi, S. J. Phys. Chem. A 2000, 104, 3878-3883. 
${ }^{\text {h} M e i e r, ~ M . ~ S . ; ~ B e r g o s h, ~ R . ~ G . ; ~ G a l l a g h e r, ~ M . ~ E . ; ~ S p i e l m a n n, ~ H . ~ P . ; ~ W a n g, ~ Z . ~ J . ~ O r g . ~ C h e m . ~ 2002, ~ 67, ~}$ 5946-5952. See also: Chen, J.; Cai, R.-F.; Huang, Z.-E.; Wu, H.-M.; Jiang, S.-K.; Shao, Q.-F. J. Chem. Soc., Chem. Commun. 1995, 1553-1554; Siedschlag, C.; Luftmann, H.; Wolff, C.; Mattay, J. Tetrahedron 1999, 55, 7805-7818; Wang, Z.; Meier, M. S. J. Org. Chem. 2003, 68, 3043-3048.

${ }^{\mathrm{i}}$ Kadish, K. M.; Gao, X.; Van Caemelbecke, E.; Suenobu, T.; Fukuzumi, S. J. Phys. Chem. A 2000, 104, 3878-3883. See also: Meier, M. S.; Bergosh, R. G.; Gallagher, M. E.; Spielmann, H. P.; Wang, Z. J. Org. Chem. 2002, 67, 5946-5952.

\section{1,2- and 1,4-addition patterns in di- and higher substituted derivatives of $\mathrm{C}_{60}$ and $\mathrm{C}_{70}$}

In the di- and higher substituted derivatives of $\mathrm{C}_{60}$ and $\mathrm{C}_{70}, 1,4$-addition appears to be more common than 1,2-addition. Relatively few examples of 1,2-addition in $\mathrm{C}_{60}$ 13b,14c,15a,16c,23a,24a and $\mathrm{C}_{70}{ }^{15 b}$ have been reported, although the calculated heats of formation of the 1,2-dimethyl and 1,4-dimethyl derivatives of $\mathrm{C}_{60}$ are practically the same, with the 1,4 - isomer calculated to be $0.3 \mathrm{kcal} \mathrm{mol}^{-1}$ lower in each report. $^{25}$ (1,6-Addition across the bond shared by a 6-membered ring and a 5-membered ring is very energetically unfavorable. ${ }^{25}$ ) The 1,2-addition pattern has also been observed in $\mathrm{C}_{60}$ derivatives bearing four benzyl $1^{23 a}$ or six methyl ${ }^{24 a}$ or six allyl ${ }^{15 a}$ substituents. Clearly, 1,2- as well as 1,4-addition has to be kept in mind in interpreting the spectra of dodecylated SWNTs.

With fullerenes, the addition pattern is sensitive to the nature of the fullerene as well as the addend. While six methyl groups add to $\mathrm{C}_{60}$ via one 1,2-addition and two 1,4-addition patterns, ${ }^{24 a}$ six methyl groups add to $C_{70}$ via only 1,4 -addition patterns. ${ }^{13 c}$ While eight

methyl groups add to $\mathrm{C}_{60}{ }^{24 \mathrm{a}}$ or to $\mathrm{C}_{70}{ }^{13 \mathrm{c}, 24 \mathrm{~b}}$ via only 1,4-addition patterns, the locations of the four 1,4addition sites differ in the two fullerenes. In a complex mixture containing different $(n, m) \mathrm{SWNTs}$, there is the potential for various addition patterns of pairs of alkyl groups.

\section{Estimating the quaternary aliphatic carbon chemical shift in dodecylated SWNTs}

In addition to the approach described in the main text, another approach to estimating the quaternary aliphatic carbon chemical shift is to compare the quaternary carbon chemical shift data for trans-10b,10c-dimethyl-10b,10c-dihydropyrene $(\mathbf{1 a}, \delta 30.0)^{17 \mathrm{a}}$ and trans-10b-methyl-10c-undecyl- 
10b,10c-dihydropyrene (1d, $\delta 33.56$ for C-10c). ${ }^{17 \mathrm{e}}$ Replacing the $10 \mathrm{~b}$-methyl group with another undecyl group would be expected to exert negligible $\gamma$-shielding and longer-range effects on C-10c.

Thus, for long chain alkyl groups, the quaternary aliphatic carbon chemical shift in a trans10b,10c-dialkyl-10b,10c-dihydropyrene can be expected between $\delta 34$ and $\delta 35$, while in the corresponding cis isomer--the isomer more relevant for analyzing the ${ }^{13} \mathrm{C}$ NMR spectra of dodecylated SWNTs--the shift might be closer to $\delta 39$. Unfortunately, there do not appear to be any reports of ${ }^{13} \mathrm{C}$ chemical shifts in a cis/trans pair of dialkyldihydro derivatives of large planar condensed aromatic hydrocarbons allowing a direct comparison.

It is not surprising that the quaternary aliphatic carbon chemical shift in trans-and cisdialkyldihydropyrene isomers would be different, as the three-dimensional structure of the ring system markedly differs for these isomers. In the trans isomer, the $\mathrm{sp}^{2}$ carbons on the periphery of the ring system are nearly planar, ${ }^{17 \mathrm{c}, \mathrm{h}}$ but the interior quaternary aliphatic carbons are significantly displaced out of this plane in order to be in a more tetrahedral environment. In contrast, in the cis isomer, the ring system has a bowl shape with the interior quaternary aliphatic carbons at the top of the inverted bowl, and the attached alkyl groups point up away from the convex face. ${ }^{17 \mathrm{~g}, 20}$ The cis isomer adopts this energetically more favorable bowl shape to reduce angle strain at the quaternary aliphatic carbons and to move the alkyl groups further apart. Torsional strain in the central ethano moiety from the eclipsed alkyl groups can be relieved by rotation about the central $\mathrm{C}-\mathrm{C}$ bond as long as this reduction in strain does not exceed the resulting increase in torsional strain on the $\mathrm{sp}^{2}$ carbons on the periphery of the ring system.

The observed (isotropic) chemical shift, $\delta_{\text {iso }}$, is the average of the three principal values of the chemical shift tensor: $\delta_{\text {iso }}=\left(\delta_{11}+\delta_{22}+\delta_{33}\right) / 3$. The three principal values lie along three mutually perpendicular directions in space. The chemical shift tensor is well known to be sensitive to local structure; modest changes in bond distances and bond angles can lead to variations in the calculated principal values of the chemical shift tensor and, therefore, in the isotropic chemical shift. ${ }^{11}$

\section{Ring current effects on ${ }^{13} \mathrm{C}$ and ${ }^{1} \mathrm{H}$ chemical shifts}

Further complicating the analysis of the quaternary aliphatic carbon chemical shifts is the presence of ring currents in the dodecylated SWNTs. These ring currents are expected to be substantial in light of previous work comparing the chemical shifts of functional groups in correspondingly 
functionalized $\mathrm{C}_{60}$ and SWNTs. ${ }^{3 \mathrm{p}}$ As noted earlier, a range of quaternary aliphatic carbon chemical shifts is observed in model compounds. The ${ }^{13} \mathrm{C}$ chemical shifts of the quaternary aliphatic carbon and its alkyl substituent are very sensitive to ring current effects, as shown by the examples in Figure S-5 for trans-10b,10c-dimethyl-10b,10c-dihydropyrene and various benzannelated derivatives.

One can assume that a corresponding sensitivity in the ${ }^{13} \mathrm{C}$ chemical shifts would be shown by cis-dimethyldihydropyrene derivatives in light of the sensitivity of methyl proton chemical shifts to ring currents in these compounds, as shown by the examples in Figure S-6 for cis-10b,10c-dimethyl-10b,10cdihydropyrene and two benzannelated derivatives. (The methyl groups bonded to the quaternary aliphatic carbons in $\mathbf{2}$ give a signal at $\delta-1.78 .{ }^{17 \mathrm{~g}}$ ) 


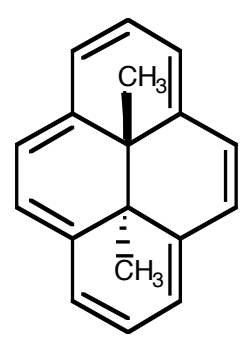

quat 29.9

$\mathrm{CH}_{3} 14.0$

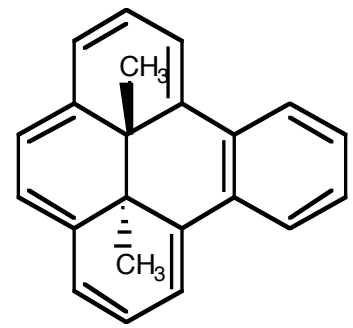

quat 35.2

$\mathrm{CH}_{3} 16.8$<smiles>C[C@]12C3=CC=CC(=Cc4cc5ccccc5cc41)C2=CC=C3</smiles>

quat 38.8

$\mathrm{CH}_{3} 19.2$

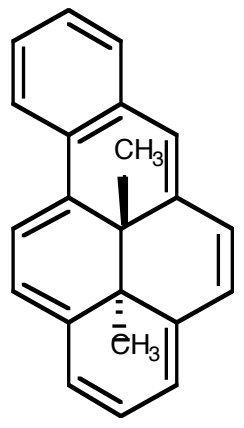

quat $36.0,35.5$

$\mathrm{CH}_{3} 17.7,17.0$

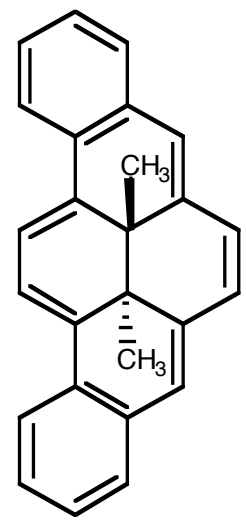

quat 39.5

$\mathrm{CH}_{3} 19.2$

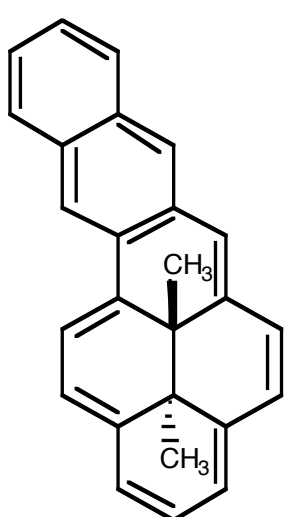

quat $38.9,38.0$

$\mathrm{CH}_{3}$ 19.5, 18.6

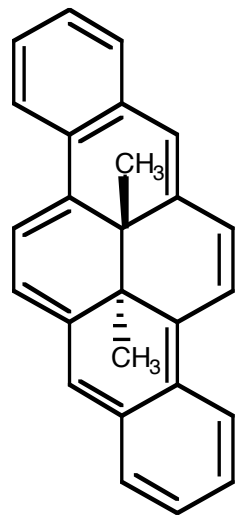

quat 32.8

$\mathrm{CH}_{3} 15.9$

Figure S-5. Quaternary aliphatic and methyl carbon chemical shifts in various transdimethyldihydropyrene derivatives. ${ }^{17 \mathrm{~h}}$ 


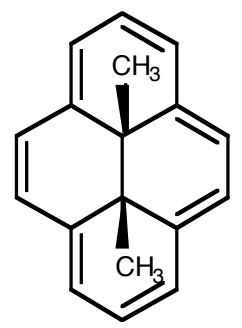

$-2.06$

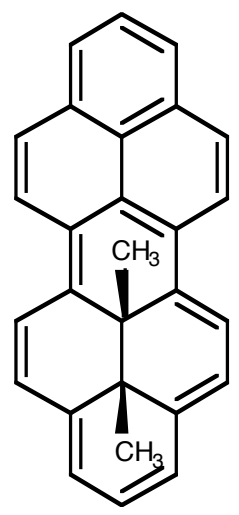

$-1.85,-2.14$

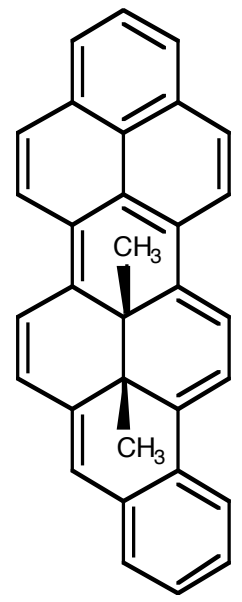

$-0.10,-0.14$

Figure S-6. Methyl proton chemical shifts in various cis-dimethyldihydropyrene derivatives. ${ }^{17 \mathrm{c}, 19 \mathrm{a}, 19 \mathrm{c}}$ 
It follows that the precise nature of the aromatic ring system around each pair of dodecylsubstituted quaternary aliphatic carbons in the derivatized SWNTs will significantly influence the chemical shift of those quaternary aliphatic carbons. This accounts, in part, for the range of quaternary aliphatic carbon chemical shifts observed from each sample of dodecylated SWNTs.

If the ring current is significantly disrupted by the presence of two pairs of dodecyl substituents close to one another, almost $10 \mathrm{ppm}$ of additional deshielding of the quaternary aliphatic carbon would be expected, ${ }^{17 a}$ probably resulting in quaternary aliphatic carbons downfield of $\delta 45$ in the dodecylated SWNTs. However, with one dodecyl group added on average for every 24, 13, and 25 nanotube $\mathrm{sp}^{2}$ carbons in the Li/ $\mathrm{NH}_{3}, \mathrm{Na} / \mathrm{NH}_{3}$, and $\mathrm{K} / \mathrm{NH}_{3}$ reductive dodecylation reactions, frequent clustering of two pairs of dodecyl groups does not seem likely.

A more likely reason for the appearance of aliphatic signal intensity downfield of $\delta 40$ is simply that $\mathrm{CH}_{2}$ groups near the surface of the SWNT give highly broadened signals because of their proximity to the nanotube. ${ }^{3 p}$ The aliphatic signals have a pronounced upfield tail as well, particularly noticeable in the $\mathrm{CP}$ spectra (Figures $6 \mathrm{~b}, 7 \mathrm{~b}$, and $8 \mathrm{~b}$ ). This broadening is not present in the $\mathrm{CP}$ spectra of the model compounds (Supporting Information, Figures S-2 and S-3). The intensity upfield of about $\delta 12$ in the CP spectra of the dodecylated SWNTs cannot be attributed to a typical dodecyl carbon chemical shift, and the carbons near the end of the dodecyl chains are sufficiently far from the nanotube that the shielding effect upon these carbons should be negligible. ${ }^{17 \mathrm{e}}$ Thus, a significant broadening of signals from $\mathrm{CH}_{2}$ groups near the surface of the SWNT seems the most reasonable explanation, as the two $\mathrm{CH}_{2}$ groups nearest the surface of the SWNT would be expected to be more upfield than the more interior $\mathrm{CH}_{2}$ groups in light of the $\mathrm{CH}_{2}{ }^{13} \mathrm{C}$ chemical shifts for the long chain alkyl group in trans-10b-methyl-10cundecyl-10b,10c-dihydropyrene (1d). ${ }^{17 e}$ Indeed, with the signals from the $\mathrm{CH}_{2}$ groups suppressed in the dipolar dephasing experiments (Figures $6 \mathrm{c}, 7 \mathrm{c}$, and $8 \mathrm{c}$ ), the broad aliphatic tails are no longer visible. The broad aliphatic tails in the basic CPMAS spectra and, to a lesser extent, in the direct ${ }^{13} \mathrm{C}$ pulse MAS spectra do not result from either probe background, the zirconia rotor barrel, or the Kel-F rotor cap, as obtaining a CPMAS spectrum or a direct ${ }^{13} \mathrm{C}$ pulse MAS spectrum of an empty rotor under the same conditions as for the dodecylated SWNTs gave essentially a flat baseline of noise in the aliphatic region.

It has long been known that ring current effects on the alkyl side chain are significantly smaller for cis- than for trans-dialkyldihydropyrene derivatives, based on ${ }^{1} \mathrm{H}$ NMR data for corresponding pairs 
of compounds. ${ }^{17 \mathrm{c}, 19 \mathrm{a}, \mathrm{b}, 26}$ This difference results from the alkyl group being essentially perpendicular to the aromatic plane of the trans isomer (as in 1) but further from the convex face of the aromatic ring system of the cis isomer (as in 2). This phenomenon is also well demonstrated by the methyl carbon chemical shift data for $\mathbf{3}$, the only cis-dialkyldihydropyrene derivative for which unambiguous methyl carbon chemical shift data have been reported: ${ }^{17 \mathrm{c}}$

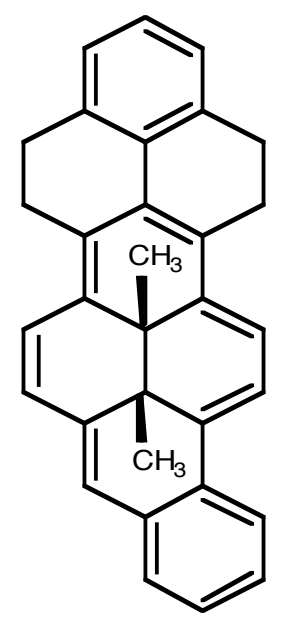

Among the dialkyldihydropyrene derivatives, 3 gives relatively deshielded methyl signals at $\delta_{\mathrm{H}^{-}}$ 0.08 and $\delta_{\mathrm{H}^{-}}-0.21$ and $\delta_{\mathrm{C}} 26.8$ and $\delta_{\mathrm{C}} 25.0$. To put these ${ }^{1} \mathrm{H}$ shifts in perspective, note that in the corresponding trans isomer, both methyl groups give a signal at $\delta-1.41$. $\left({ }^{13} \mathrm{C}\right.$ chemical shifts were not reported for the trans isomer.) To put the methyl ${ }^{13} \mathrm{C}$ shifts of 3 in perspective, note that the signals for the methyl carbons of numerous trans-dimethyldihydro derivatives of planar condensed aromatic hydrocarbons (including those with only alkyl substituents on the periphery) range from $\delta 14-20 .{ }^{17}$

Not surprisingly, for a specific trans-dialkyldihydropyrene derivative with ethyl or longer aliphatic side chains, the ${ }^{1} \mathrm{H}$ signals become steadily less shielded moving away from the aromatic ring system. ${ }^{17 \mathrm{a}, \mathrm{e}, 27}$ A considerably more complicated situation holds for the corresponding ${ }^{13} \mathrm{C}$ chemical shifts if long alkyl side chains are present. ${ }^{17 \mathrm{e}}$ However, the methyl groups terminating the dodecyl chains are sufficiently far from the nanotube that the shielding effect upon the methyl groups is negligible. $^{17 \mathrm{e}}$ 
23. (a) Kadish, K. M.; Gao, X.; Van Caemelbecke, E.; Suenobu, T.; Fukuzumi, S. J. Am. Chem. Soc. 2000, 122, 563-570; (b) Kadish, K. M.; Gao, X.; Gorelik, O.; Van Caemelbecke, E.; Suenobu, T.; Fukuzumi, S. J. Phys. Chem. A 2000, 104, 2902-2907.

24. (a) Al-Matar, H.; Abdul-Sada, A. K.; Avent, A. G.; Fowler, P. W.; Hitchcock, P. B.; Rogers, K. M.; Taylor, R. J. Chem. Soc., Perkin Trans 2 2002, 53-58; (b) Darwish, A. D.; de Guio, P.; Taylor, R. Fullerenes, Nanotubes, and Carbon Nanostructures 2002, 10, 261-272.

25. (a) Nagashima, H. ; Saito, M.; Kato, Y.; Goto, H.; Osawa, E.; Haga, M.; Itoh, K. Tetrahedron 1996, 52, 5053-5064; (b) Clare, B. W.; Kepert, D. L. J. Mol. Struct. (Theochem) 2003, 621, 211-231.

26. (a) Boekelheide, V.; Phillips. J. B. J. Am. Chem. Soc. 1967, 89, 1695-1704; (b) Phillips, J. B.; Molyneux, R. J.; Sturm, E.; Boekelheide, V. J. Am. Chem. Soc. 1967, 89, 1704-1709.

27. (a) Harris, T. D.; Neuschwander, B.; Boekelheide, V. J. Org. Chem. 1978, 43, 727-730; (b) Tashiro, M.; Yamato, T. J. Org. Chem. 1982, 47, 2783-2785; (c) Tashiro, M.; Yamato, T. J. Am. Chem. Soc. 1982, 104, 3701-3707. 